\title{
Papillary tumour of the pineal region: a case report
}

\author{
Michael Bromfield ${ }^{1 *}$, Christos Profyris², Aadila Mehtar ${ }^{3}$, Marna Du Toit $^{3}$ and Reubina Wadee ${ }^{4}$
}

\begin{abstract}
Background: Papillary tumor of the pineal region is an unusual, recently described entity with potential for misinterpretation as either an ependymoma or choroid plexus papilloma. With few reported cases, there is little data regarding the biologic behavior, natural course and optimal treatment for these patients. Further accumulation of reports will assist with defining this entity and may provide further insight into management of such patients.

Case presentation: This patient was a 24-year-old male with new onset seizures and a decreased level of consciousness. MRI scan showed a large heterogeneously enhancing solid-cystic mass in the pineal region extending to the third ventricle.

Discussion: Papillary tumor of the pineal region is a neuroepithelial tumor with distinct morphological and immunohistochemical features that can be utilized to help differentiate it from other primary and metastatic tumors occurring within this region. Although there is currently no clear consensus, the potential for disease progression and CSF dissemination supports early aggressive therapy in these patients.
\end{abstract}

Keywords: Brain tumor, Papillary tumor of the pineal region, Neuro-oncology

\section{Background}

Tumors of the pineal region are uncommon and account for less than $1 \%$ of central nervous system (CNS) neoplasms in adults [1]. Similarly, papillary tumors primarily located in the CNS are just as rare. As a result, tumors with a papillary morphology in the pineal region are exceptional and seldom encountered in general histopathological practice. With only 181 described cases according to the 2016 edition of the World Health Organization (WHO) Classification of Tumors of the CNS, papillary tumor of the pineal region is a recently described entity that is important to recognize due to the potential for misinterpretation as either an ependymoma or choroid plexus papilloma [2]. In this report, we describe the presentation, management, and histopathological features of a case of a papillary tumor of the pineal region.

\footnotetext{
* Correspondence: mjbromfield@yahoo.com

'Department of Anatomical Pathology, University of the Witwatersrand, Johannesburg, South Africa

Full list of author information is available at the end of the article
}

\section{Case presentation}

This patient was a 24-year-old male who presented with new onset seizures and drowsiness secondary to hydrocephalus. He had a history of pulmonary tuberculosis for which he was undertaking treatment. On examination, the patient had a Glasgow Coma Scale of 7/15. The patient was intubated and had an urgent CT scan of his brain, which demonstrated acute hydrocephalus and the tumor. The patient was treated with an endoscopic third ventriculostomy to address the hydrocephalus and following the procedure his conscious level improved and he was extubated. Clinical examination at this point revealed Parinaud's syndrome and an MRI characterized the tumor further. He had a subtotal resection of his tumor as it was entrenched around the internal cerebral veins and basal veins of Rosenthal. Following surgery, adjuvant stereotactic radiosurgery was planned. Unfortunately the patient demised within 3-month follow-up.

Magnetic resonance imaging (Fig. 1a, b) showed an aggressive pineal parenchymal complex lesion. There was a large heterogeneously enhancing solid-cystic mass in the 


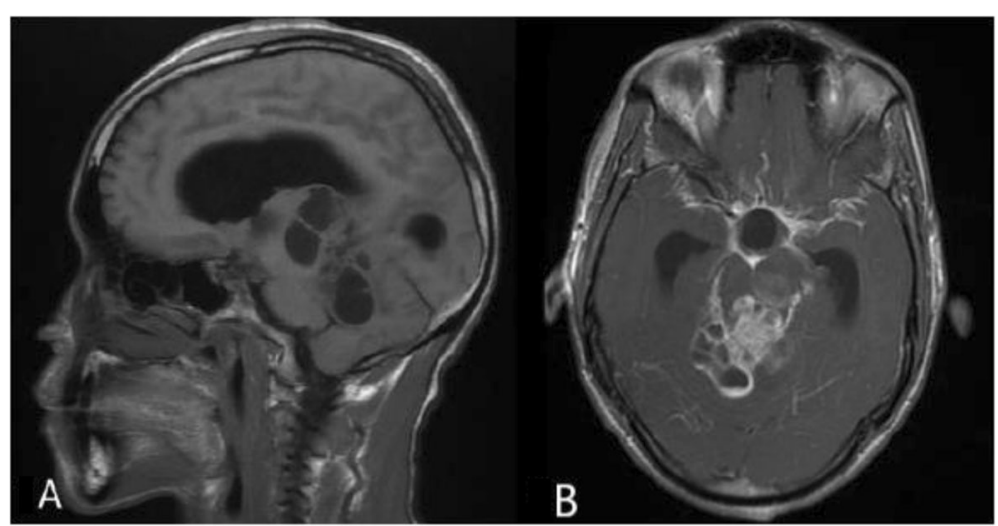

Fig. 1 a Sagittal T1-FLAIR. b Axial T1-weighted magnetic resonance imaging (MRI)

pineal region, with no foci of calcification. The cystic component was multi-loculated and obstructed the third and fourth ventricle with associated hydrocephalus. The mass measured $5.8 \times 3.5 \times 4.4 \mathrm{~cm}$. Post-operative imaging was not performed.

Microscopic examination revealed multiple portions of tissue demonstrating a neoplasm with a papillary and solid architecture (Fig. 2a, b). In the papillary areas, vessels were surfaced by large pale to eosinophilic, cuboidal to columnar cells. These cells had well-defined cell membranes and vacuolated cytoplasm. The nuclei were located at the basal pole and were round to oval in shape with finely stippled chromatin (Fig. 2c, d). Occasional cells showed nuclear indentation. Nucleoli were visible at higher magnification. Mitotic activity was not readily identified. The vessels appeared hyalinised. There was no microvascular proliferation. No areas of necrosis were identified.

Immunohistochemistry for cytokeratins (AE1/AE3 and CAM5.2) was positive (Fig. 3a, b). Focal positive staining with glial fibrillary acidic protein (GFAP) was noted. The tumor also stained with Vimentin and S100 protein. There was strong expression of neural cell adhesion molecule 1 (NCAM1). There was no membrane, dot-, or ring-like epithelial membrane antigen (EMA) immunoreactivity which is typically encountered in ependymomas. Sal-like protein 4 (SALL4), a germ cell marker, was negative

On ultrastructural examination, cells with peripherally located nuclei were identified. The nuclear contours were irregular and indented (Fig. 4a, b). Prominent nucleoli were identified. Intermediate filaments were noted

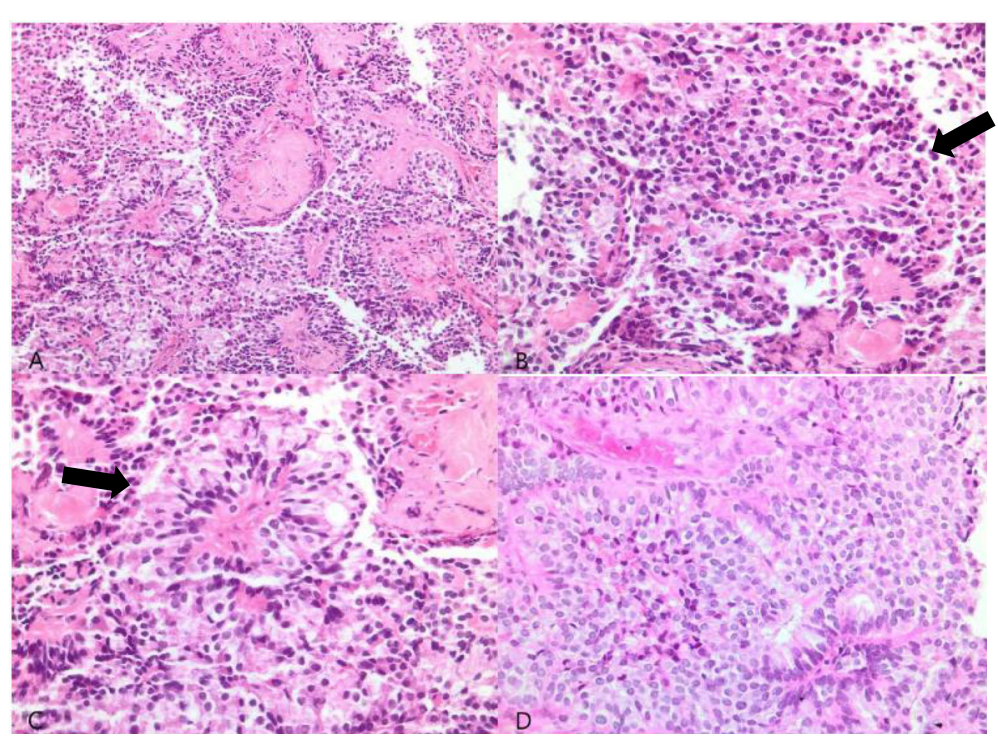

Fig. 2 Photomicrographs showing histopathological features of the tumor (hematoxylin and eosin staining). Papillary regions demonstrated with arrows 


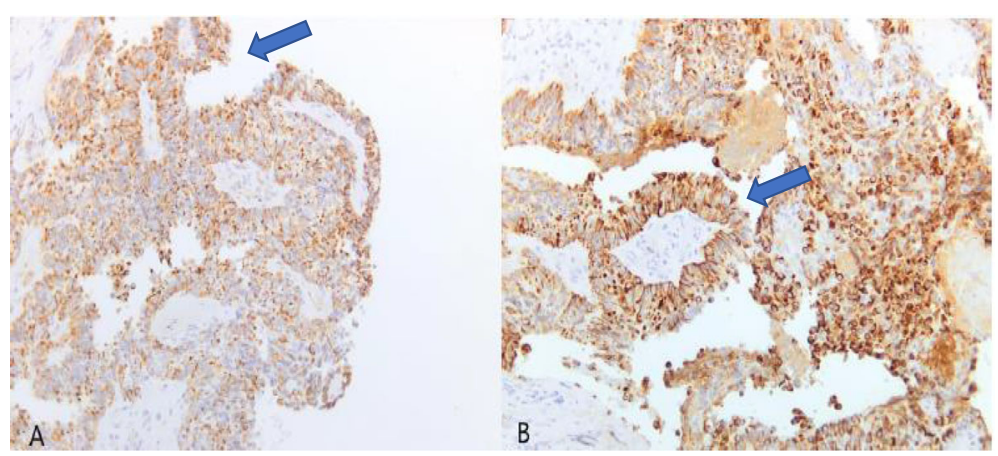

Fig. 3 Photomicrograph showing immunohistochemical staining characteristics. Positive regions stain brown. Papillary regions demonstrated with arrows

in the cytoplasm of cells near the nucleus. Microvilli were abundant (Fig. 4c). Rough endoplasmic reticulum was identified in parallel (Fig. 4d). There was an isolated dense core vesicle

\section{Discussion}

As defined by the WHO, papillary tumor of the pineal region is "a neuroepithelial tumor localized in the pineal region and characterized by a combination of papillary and solid areas with epithelial-like cells and immunoreactivity for cytokeratins" [2]. It is frequently localized in the third ventricle and extends above the quadrigeminal cistern, causing triventricular hydrocephalus.

As surmised by its name, papillary tumor of the pineal region does not arise from the pineal gland, but rather, is thought to originate from specialized secretory ependymocytes of the subcommissural organ [3]. Located in the posterior region of the third ventricle, the subcommissural organ is a circumventricular organ of the brain with a glandular structure [4]. The theory that papillary tumor of the pineal region arises from this region is confirmed by Shibahara and colleagues who showed expression of proteins presumed to be secreted by cells of the human subcommissural organ [5]. The papillary architecture of this tumor mimics subcommissural organ morphology. In addition, the ependymal cells from this region in infants are typically immunoreactive for cytokeratin, EMA, and S100 protein. In adults, these cells may remain vestigial in the subcommissural organ and have been proposed to have a role in the histogenesis of this neoplasm [6].

Papillary tumor of the pineal region shows distinct chromosomal alterations and DNA methylation and expression profiles. Losses of chromosomes 10, 3, and 22q have been described. In addition, gains in chromosomes $8 \mathrm{p}$ and 12 have also been identified [7]. Recently,

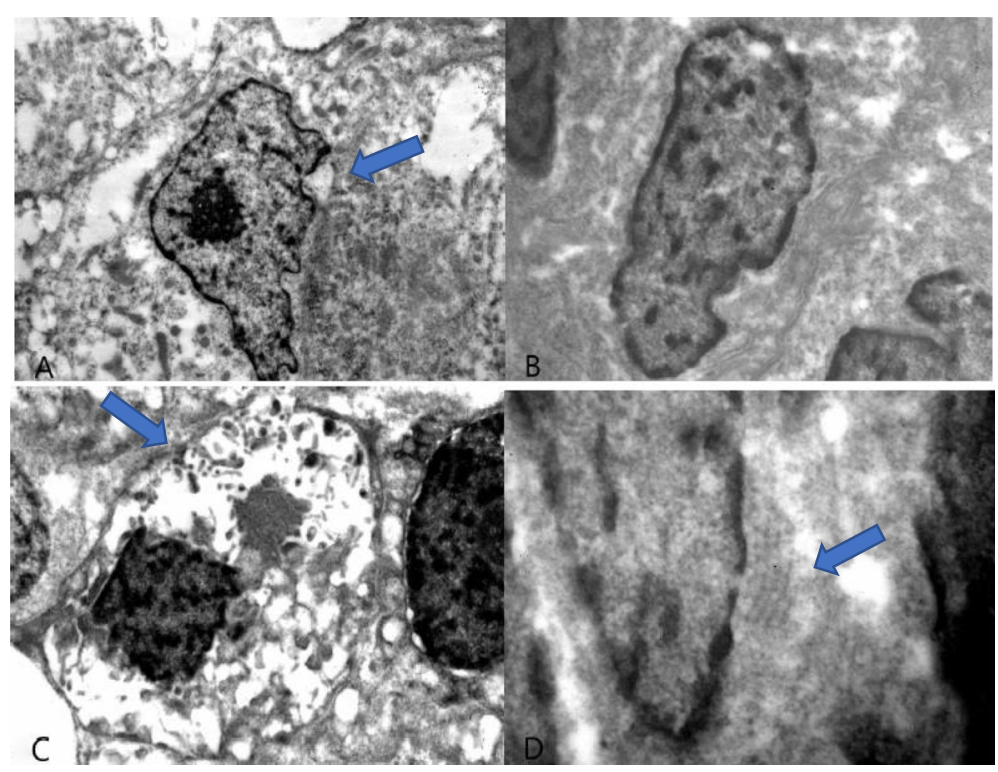

Fig. 4 Ultrastructural features of the tumor 
Goschzik and colleagues, have described phosphatase and tensin homolog (PTEN) mutation and activation of PI3K/Akt/Mtor pathway in the pathogenesis [8].

While papillary tumor of the pineal region may share common features with other primary and metastatic tumors involving the central nervous system, distinct morphological, immunohistochemical, and molecular features may assist with the diagnosis of this entity. Papillary tumors of the pineal region are immunoreactive against cytokeratins, S100 protein, neuron-specific enolase (NSE), and vimentin. There is variable staining for EMA, with Jouvet and colleagues reporting weak positivity in tumor cells and focal cell surface staining especially on the pole facing the vessel or lumen of rosettes or tubes. GFAP is negative in tumor cells. However, weak expression may be noted in the perivascular region, at the periphery of the tumor or by entrapped reactive astrocytes [6]. Microtubule-associated protein 2 (MAP-2) staining has also been reported [9].

A frequent differential when considering the diagnosis of a papillary tumor of the pineal region is a papillary ependymoma. Jouvet and colleagues noted that the papillary structure of papillary tumor of the pineal region have more of an epithelial character and lack a fibrillary background when compared with an ependymoma. In contrast to papillary tumor of the pineal region, ependymomas express GFAP and only broad spectrum cytokeratin (AE1/AE3). As compared with ependymal tumors, papillary tumors of the pineal region overexpress SAM pointed domain containing ETS transcription factor (SPDEF) [7].

Immunohistochemical staining in a papillary tumor of the pineal region may be comparable with tumors of the choroid plexus. Morphologically however, the appearance of papillary tumor of the pineal region is less papillary than in a choroid plexus papilloma and more differentiated than a choroid plexus carcinoma. Although both choroid plexus papilloma and papillary tumor of the pineal region have broad fibrovascular cores, the columnar cells of papillary tumor of the pineal region are surrounded by a diffuse cellular proliferation. If available, immunohistochemical staining for transthyretin is typically strong in tumors of the choroid plexus but weak or negative in papillary tumor of the pineal region. In addition, papillary tumor of the pineal region shows negative membranous Kir7.1 staining and negative cytoplasmic stanniocalcin-1 staining, which both are frequently encountered in choroid plexus tumors [9].

Electron microscopy may assist with the diagnosis of papillary tumor of the pineal region by identifying features proposing its ependymal and secretory nature. Ependymal differentiation is suggested by identification of microvilli and zipper-like junctions. Rough endoplasmic reticulum and dilated cisternae with granular material suggest a secretory function. The dense core vesicle, indented and lobulated nucleus and numerous mitochondria help differentiate papillary tumor of the pineal region from tumors of the choroid plexus.

Little information exists regarding the biologic behavior, natural course, and optimal treatment for these patients. It is believed that these tumors behave in a similar way to ependymomas and tumors of the choroid plexus with potential for local recurrence. Santoro and colleagues provided some information regarding the natural history of papillary tumor of the pineal region. In their case report, neuro-radiological follow-up for a period of four years showed an average growth rate of $3.4 \mathrm{~mm}$ per year [10]. Fèvre-Montange and colleagues followed 29 of 31 patients for a mean follow-up period of 4.2 years. In their study, 21 patients experienced disease progression and 8 patients died. There was one patient who had early CSF dissemination [11]. Sato and colleagues similarly reported a case with early CSF dissemination [12]. Although there is currently no clear consensus, early aggressive multifaceted treatment with a combination of surgical resection, stereotactic radiosurgery, and chemotherapy may be advocated for tumor control.

The patient presented in this case report demised before follow-up and a post mortem examination was not performed to clarify a cause of death. Further accumulation of case reports will assist with defining this entity and may provide further insight into management of such patients.

\section{Acknowledgements}

Not applicable.

Authors' contributions

All authors contributed equally in the development of this case report. All authors read and approved the final manuscript.

Funding

No funding was received.

Availability of data and materials

Not applicable. Data sharing is not applicable to this report as no datasets were generated.

Machines used:

1. MRI Scanner

Brand: General Electric (GE) Healthcare

Model: Signa Optima MR360

Country: China

2. Immunohistochemical slide stainer

Brand: Dako Agilent Autostainer Link 48

Model: AS48430

Country: Denmark

3. Electron Microscopy:

Brand: JEOL

Model: JEM - 1011

Country: Japan

Ethics approval and consent to participate

Ethics approval for this case report has been obtained (M1809100) from the Human Research Ethics Committee at the University of the Witwatersrand. Please see attached ethics approval certificate. 


\section{Consent for publication}

Not applicable. The patient demised shortly following surgery and consent from the patient was not obtained. In addition, the next of kin could not be contacted for consent. To ensure this patient remains anonymous, all images included in this report are entirely unidentifiable. Additionally, the patient details have not been recorded in this case report.

\section{Competing interests}

The authors declare that they have no competing interests.

\section{Author details}

${ }^{1}$ Department of Anatomical Pathology, University of the Witwatersrand, Johannesburg, South Africa. ${ }^{2}$ Helen Joseph Hospital, Johannesburg, South Africa. ${ }^{3}$ Department of Diagnostic Radiology, University of the Witwatersrand, Johannesburg, South Africa. ${ }^{4}$ National Health Laboratory Service (NHLS), Department of Anatomical Pathology, University of the Witwatersrand, Johannesburg, South Africa.

Received: 9 January 2020 Accepted: 2 June 2020

Published online: 17 June 2020

\section{References}

1. Smith AB, Rushing EJ, Smirniotopoulos JG. From the archives of the AFIP: lesions of the pineal region: radiologic-pathologic correlation. Radiographics [Internet]. 2010 Nov;30(7):2001-20. Available from: http://www.ncbi.nlm.nih. gov/pubmed/21057132.

2. Louis D, Ohgaki H, Wiestler O, Cavenee WK. WHO Classification of tumours of the central nervous system 4th Edition Revised, Volume 1. 2016. 180-182 p.

3. Chang AH, Fuller GN, Debnam JM, Karis JP, Coons SW, Ross JS, et al. MR Imaging of Papillary Tumor of the Pineal Region. Am J Neuroradiol [Internet]. 2008 Jan; 29(1):187-9. Available from: http://www.ajnr.org/lookup/doi/10.3174/ajnr.A0784.

4. Rodríguez EM, Rodríguez S, Hein S. The subcommissural organ. Microsc Res Tech [Internet]. 1998 Apr 15;41(2):98-123. Available from: http://doi.wiley. com/10.1002/\%28SICl\%291097-0029\%2819980415\%2941\%3A2\%3C98\%3A\%3 AAID-JEMT2\%3E3.0.CO\%3B2-M.

5. Shibahara J, Todo T, Morita A, Mori H, Aoki S, Fukayama M. Papillary neuroepithelial tumor of the pineal region. A case report. Acta Neuropathol [Internet]. 2004 Oct 19;108(4):337-40. Available from: http://link.springer. com/10.1007/s00401-004-0898-z.

6. Jouvet A, Fauchon F, Liberski P, Saint-Pierre G, Didier-Bazes M, Heitzmann A, et al. Papillary tumor of the pineal region. Am J Surg Pathol [Internet]. 2003 Apr;27(4): 505-12. Available from: http://www.ncbi.nlm.nih.gov/pubmed/12657936.

7. Heim S, Sill M, Jones DTW, Vasiljevic A, Jouvet A, Fèvre-Montange $M$, et al. Papillary Tumor of the Pineal Region: A Distinct Molecular Entity. Brain Pathol [Internet]. 2016 Mar;26(2):199-205. Available from: http://www.ncbi. nlm.nih.gov/pubmed/26113311.

8. Goschzik T, Gessi M, Denkhaus D, Pietsch T. PTEN mutations and activation of the PI3K/Akt/mTOR signaling pathway in papillary tumors of the pineal region. J Neuropathol Exp Neurol [Internet]. 2014 Aug;73(8):747-51. Available from: http://www.ncbi.nlm.nih.gov/pubmed/25003235.

9. Hasselblatt M, Blumcke I, Jeibmann A, Rickert CH, Jouvet A, van de Nes JAP, et al. Immunohistochemical profile and chromosomal imbalances in papillary tumours of the pineal region. Neuropathol Appl Neurobiol [Internet]. 2006;32(3):278-83 Available from: http://doi.wiley.com/10.1111/j.1365-2990.2006.00723.x.

10. Santoro A, D'Elia A, Fazzolari B, Santoro F, Antonelli M, Giangaspero F, et al. Four-year clinical and neuroradiological follow-up of a papillary tumor of the pineal region. Neurol Sci [Internet]. 2012 Aug 29;33(4):931-5. Available from: http://link.springer.com/10.1007/s10072-011-0860-5.

11. Fèvre-Montange $M$, Hasselblatt M, Figarella-Branger $D$, Chauveinc $L$, Champier J, Saint-Pierre G, et al. Prognosis and histopathologic features in papillary tumors of the pineal region: a retrospective multicenter study of 31 cases. J Neuropathol Exp Neurol [Internet]. 2006 Oct;65(10):1004-11. Available from: http://www.ncbi.nlm.nih.gov/pubmed/17021405.

12. Sato TS, Kirby PA, Buatti JM, Moritani T. Papillary tumor of the pineal region: report of a rapidly progressive tumor with possible multicentric origin. Pediatr Radiol [Internet]. 2009 Feb 27;39(2):188-90. Available from: http:// link.springer.com/10.1007/s00247-008-1060-1.

\section{Publisher's Note}

Springer Nature remains neutral with regard to jurisdictional claims in published maps and institutional affiliations.

\section{Submit your manuscript to a SpringerOpen ${ }^{\odot}$ journal and benefit from:}

- Convenient online submission

- Rigorous peer review

- Open access: articles freely available online

- High visibility within the field

- Retaining the copyright to your article

Submit your next manuscript at $\boldsymbol{\nabla}$ springeropen.com 